\title{
Sensorless Scalar-Controlled Induction Motor Drives With Modified Flux Observer
}

\author{
Chun-Chieh Wang and Chih-Hsing Fang
}

\begin{abstract}
This paper presents a simple sensorless scalar control algorithm to control the speed of an induction motor. First, a modified flux observer was employed to estimate the stator flux with the voltage command and the feedback current. Then, based on the mathematical model of the induction motor, the slip frequency was calculated, and the frequency of the voltage command was compensated. An auto-boost controller was designed to overcome the decrease in voltages of the stator resistance and to maintain constant stator flux amplitude. To improve the pure integration problem, a highpass filter was installed in the stator flux observer. In this filter, the cut-off frequency is proportional to the voltage frequency; therefore, the phase shift and amplitude degradation of the estimated flux can be corrected easily. Finally, to demonstrate the proposed control algorithm, a PC-based experimental system was constructed in a 1-hp induction motor. Experimental results are presented to validate the effectiveness of our design.
\end{abstract}

Index Terms-Flux observer, induction motor, scalar control, sensorless control, slip estimator.

\section{INTRODUCTION}

I $\mathrm{N}$ recent years, industrial applications of the inverter-fed induction motor driver have obviously increased. In driver control design, both the scalar and vector control methods are applied extensively. Notably, speed response, operating scope, and speed accuracy of the latter are superior to the former [1], [2]. However, the scalar control method has a simple control structure and is implemented easily, and thus, within generalpurpose industrial applications, it is applied broadly. To improve speed control performance of the scalar control method, an encoder or speed tachometer is required to feedback the rotor angle or rotor speed signal and compensate the slip frequency. However, it is expensive and destroys the mechanical robustness of the induction motor.

Recently, sensorless control of the induction motor has been focused on and developed. Many superior sensorless control methods have been proposed [3]-[8]. For example, Bonanno et al. [3] employed a parallel structured rotor flux estimator to avoid the pure integration problem as well as correct the phase shift and amplitude degradation of the estimated flux. Schauder [4] applied the model reference adaptive system to estimate the

Manuscript received November 13, 2000; revised February 14, 2002. This work was supported in part by the National Science Council of the Republic of China under Contract NSC89-2218-E-231-002.

C.-C. Wang is with the Department of Electrical Engineering, Ching Yun Institute of Technology, Jung-Li, Taiwan, R.O.C. (e-mail: wangchih@ ms42.hinet.net).

C.-H. Fang is with the Department of Electronic and Control Engineering, National Chiao Tung University, Hsinchu, Taiwan, R.O.C. (e-mail: ericf@ itri.org.tw).

Digital Object Identifier 10.1109/TEC.2002.805181 rotor speed. Based on the cross product of the estimate rotor flux vectors, which is produced by the voltage and the current model, the adaptive law regulates the estimated speed. In addition, Peng et al. [5] assumed that the instantaneous reactive power model to design a robust speed estimator, which was robust to both stator resistor variation and pure integration. Kubota and Yang et al. [6], [7], applied the full order adaptive observer to estimate motor speed and stator resistor simultaneously. Kubota et al. further injected an ac component into the flux current command to estimate the rotor resistor and speed independently. In addition, Lee et al. [8] employed the feedback stator current and the stator flux reference to estimate the slip angular frequency and calculate the motor speed. Bose et al. [9] replaced the pure integrator of the flux observer with three programmable-cascaded lowpass filters for which the bandwidth is dependent on the electric frequency. Hu et al. [10] applied the inner product of the estimate flux and the back electric magnetic force (EMF) to correct the estimated flux value. Finally, Shin et al. [11] employed a lowpass filter for which the bandwidth is proportional to the electrical frequency and a correct matrix to estimate the stator flux and rotor speed of the induction motor.

\section{INDUCTION MOTOR MODEL}

The dynamic model of an induction motor in the general $d-q$ reference frame can be described as [2]

$$
\begin{aligned}
\dot{\lambda}_{d s} & =V_{d s}-R_{s} i_{d s}+\omega \lambda_{q s} \\
\dot{\lambda}_{q s} & =V_{q s}-R_{s} i_{q s}-\omega \lambda_{d s} \\
\dot{\lambda}_{d r} & =-\frac{\lambda_{d r}}{\tau_{r}}+\left(\omega-\omega_{r}\right) \lambda_{q r}+\frac{L_{m} i_{d s}}{\tau_{r}} \\
\dot{\lambda}_{q r} & =-\frac{\lambda_{q r}}{\tau_{r}}-\left(\omega-\omega_{r}\right) \lambda_{d r}+\frac{L_{m} i_{q s}}{\tau_{r}} \\
\lambda_{d r} & =L_{r} \frac{\lambda_{d s}-\sigma L_{s} i_{d s}}{L_{m}} \\
\lambda_{q r} & =L_{r} \frac{\lambda_{q s}-\sigma L_{s} i_{q s}}{L_{m}} \\
\sigma & =1-\frac{L_{m}^{2}}{L_{s} L_{r}}, \quad \tau_{r}=\frac{L_{r}}{R_{r}}
\end{aligned}
$$

where the state variables $\left(V_{d s}, V_{q s}\right),\left(i_{d s}, i_{q s}\right),\left(\lambda_{d s}, \lambda_{q s}\right)$, and $\left(\lambda_{d r}, \lambda_{q r}\right)$, are the stator voltage, the stator current, and the stator and rotor flux, respectively. $\omega$ and $\omega_{r}$ are the angular velocity of the coordinate frame and the induction motor, respectively. Furthermore, $\tau_{r}$ and $\sigma$ represent the rotor time constant and the leakage coefficient. Finally, $R_{s}, R_{r}, L_{s}, L_{r}$, and $L_{m}$ are the stator and rotor resistor and the stator, rotor, and mutual inductance, individually. 


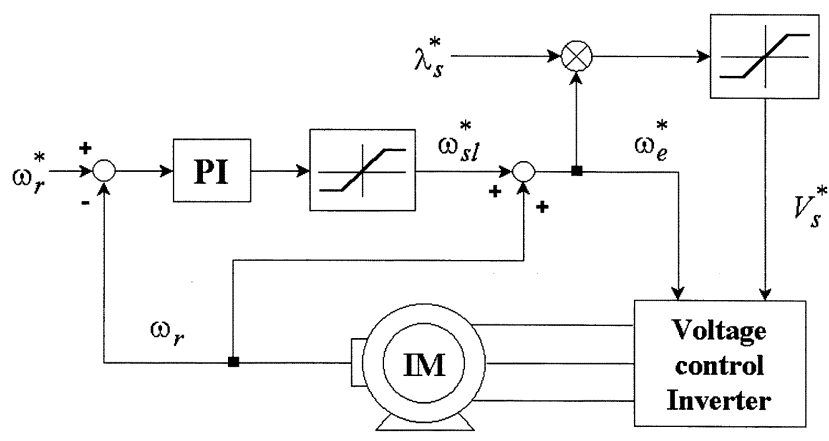

Fig. 1. Block diagram of the closed-loop scalar control system.

\section{SCALAR CONTROL}

From (1) and (2), the dynamic equations of the stator flux in the synchronous reference frame $\left(\omega=\omega_{e}\right)$ can be expressed as

$$
\begin{aligned}
& \dot{\lambda}_{d s}^{e}=V_{d s}^{e}-R_{s} i_{d s}^{e}+\omega_{e} \lambda_{q s}^{e} \\
& \dot{\lambda}_{q s}^{e}=V_{q s}^{e}-R_{s} i_{q s}^{e}-\omega_{e} \lambda_{d s}^{e}
\end{aligned}
$$

where ${ }^{e}$ denotes the variables, which are in the synchronously rotating reference frame, and $\omega_{e}$ is the synchronous angular frequency. Therefore, the steady-state values of stator flux become constant values.

Assume the stator flux vector is in phase with the $d^{e}$-axis of the synchronous reference frame and the stator flux amplitude is constant, that is

$$
\lambda_{d s}^{e}=\left|\bar{\lambda}_{s}\right|, \quad \lambda_{q s}^{e}=0, \quad \dot{\lambda}_{d s}^{e}=0
$$

Substituting (10) into (8) and (9), the stator voltage can be simplified as

$$
\begin{aligned}
& V_{d s}^{e}=R_{s} i_{d s}^{e}, \\
& V_{q s}^{e}=R_{s} i_{q s}^{e}+\omega_{e}\left|\bar{\lambda}_{s}\right| .
\end{aligned}
$$

If the voltage decrease of the stator resistor in (11) and (12) are overlooked, the magnitude correlation between the stator voltage and the stator flux can be approximated as

$$
\left|\bar{V}_{s}\right| \approx \omega_{e}\left|\bar{\lambda}_{s}\right|
$$

For a voltage-fed inverter, to ensure a constant flux value of the induction motor, the ratio of the stator voltage amplitude to the electrical frequency should be kept constant. This is the basic theory of the open-loop scalar control algorithm.

In the open-loop scalar control, the rotor speed of the induction motor varies with the load condition. Therefore, when speed accuracy is required, the closed-loop control strategy will be adopted. In the closed-loop scalar control, the speed PI controller employs the speed error signal to compensate the slip frequency and thus ensures adherence to the speed command. Fig. 1 presents, schematically, the block diagram of a closed-loop scalar control system [2], where the $\omega_{s l}^{*}$ is the compensated slip-frequency, and $\lambda_{s}^{*}$ is the stator flux command.

In Fig. 1, to compensate for the slip frequency, the speed signal must be detected. However, if the slip frequency can be estimated with the stator voltage and current, then the same purpose can be attained without the speed sensor.

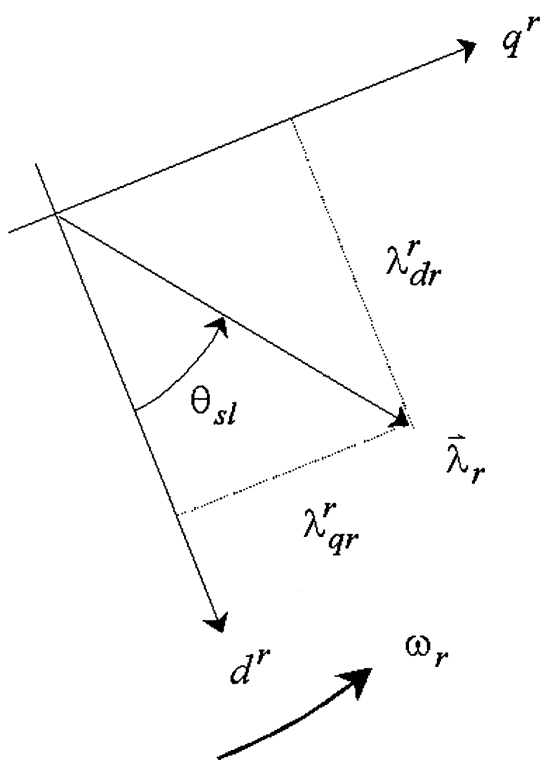

Fig. 2. Geometric relation of rotor flux in the $d^{r}-q^{r}$ reference frame.

\section{SLIP OBSERVER}

From (3) and (4), the dynamic equations of rotor flux in the rotor rotating reference frame $\left(\omega=\omega_{r}\right)$ can be expressed as

$$
\begin{aligned}
& \dot{\lambda}_{d r}^{r}=-\frac{\lambda_{d r}^{r}}{\tau_{r}}+\frac{L_{m} i_{d s}^{r}}{\tau_{r}} \\
& \dot{\lambda}_{q r}^{r}=-\frac{\lambda_{q r}^{r}}{\tau_{r}}+\frac{L_{m} i_{q s}^{r}}{\tau_{r}}
\end{aligned}
$$

where ${ }^{r}$ represents the rotor reference frame. The reference axes rotate with $\omega_{r}$; thus, the rotor flux $\lambda_{d r}^{r}$ and $\lambda_{q r}^{r}$ will vary with the slip frequency $\omega_{s l}$.

Fig. 2 illustrates the geometric relation of rotor flux in the $d^{r}-q^{r}$ reference frame. There is only one constraint on the selection of the $d^{r}$ - and $q^{r}$-axes. That is, the reference axes must rotate with $\omega_{r}$; therefore, the selection of the axes is not unique. In Fig. 2, the $\theta_{s l}$ denotes the slip angle, which is the angle between the rotor flux vector $\bar{\lambda}_{r}$ and the $d^{r}$-axis, that is

$$
\theta_{s l}=\tan ^{-1}\left(\frac{\lambda_{q r}^{r}}{\lambda_{d r}^{r}}\right)
$$

The slip frequency equals the time derivative of the slip angle of (16) and can be expressed as

$$
\omega_{s l}=\frac{d}{d t} \theta_{s l}=\frac{\lambda_{d r}^{r} \dot{\lambda}_{q r}^{r}-\lambda_{q r}^{r} \dot{\lambda}_{d r}^{r}}{\lambda_{d r}^{r 2}+\lambda_{q r}^{r 2}} .
$$

Substitute (14) and (15) into (17), and the slip frequency can be simplified as

$$
\omega_{s l}=\frac{L_{m}}{\tau_{r}} \frac{\lambda_{d r}^{r} i_{q s}^{r}-\lambda_{q r}^{r} i_{d s}^{r}}{\lambda_{d r}^{r 2}+\lambda_{q r}^{r 2}}=\frac{L_{m}}{\tau_{r}} \frac{\bar{\lambda}_{r} \otimes \bar{i}_{s}}{\bar{\lambda}_{r} \circ \bar{\lambda}_{r}}
$$

where $\otimes$ and $\circ$ denote the cross product and inner product, respectively. Substitute (5) and (6) into (18), and the slip frequency can be rewritten as

$$
\omega_{s l}=\frac{L_{m}^{2}}{L_{r}^{2}} \frac{R_{r} \bar{\lambda}_{s} \otimes \bar{i}_{s}}{\left(\bar{\lambda}_{s}-\sigma L_{s} \bar{i}_{s}\right) \circ\left(\bar{\lambda}_{s}-\sigma L_{s} \bar{i}_{s}\right)} .
$$


The calculations of the cross product and inner product with rotor reference frame or stationary reference frame in (19) are identical. Thus, the estimated stator flux in the stationary reference frame can be applied to calculate the slip frequency.

\section{STATOR FluX ObSERVER}

From (1) and (2), the dynamic equation of the stator flux in stationary reference frame $(\omega=0)$ can be expressed as

$$
\begin{aligned}
& \dot{\lambda}_{d s}^{s}=e_{d s}^{s}=V_{d s}^{s}-R_{s} i_{d s}^{s} \\
& \dot{\lambda}_{q s}^{s}=e_{q s}^{s}=V_{q s}^{s}-R_{s} i_{q s}^{s}
\end{aligned}
$$

where ${ }^{s}$ represents the stationary reference frame, and the $e_{d s}^{s}$ and $e_{q s}^{s}$ denote the $d^{s}$-axis and $q^{s}$-axis back EMF, respectively. From (20) and (21), the open-loop stator flux estimator can be designed as

$$
\begin{aligned}
& \dot{\hat{\lambda}}_{d s}^{s}=\hat{e}_{d s}^{s}=V_{d s}^{s}-R_{s} i_{d s}^{s} \\
& \dot{\hat{\lambda}}_{q s}^{s}=\hat{e}_{q s}^{s}=V_{q s}^{s}-R_{s} i_{q s}^{s}
\end{aligned}
$$

where is the estimated value.

In (22) and (23), pure integrators are applied to estimate the stator flux. Notably, initial value error and dc-offset problems exist herein. To improve these problems, the observer used to cascade a highpass filter [3], and the equations can be expressed as

$$
\begin{aligned}
& \dot{\hat{\lambda}}_{d s}^{f}=-\omega_{c} \hat{\lambda}_{d s}^{f}+\hat{e}_{d s}^{s} \\
& \dot{\hat{\lambda}}_{q s}^{f}=-\omega_{c} \hat{\lambda}_{q s}^{f}+\hat{e}_{q s}^{s}
\end{aligned}
$$

where $\hat{\lambda}_{d s}^{f}$ and $\hat{\lambda}_{q s}^{f}$ are the $d^{s}$ - and $q^{s}$-axes estimated flux with highpass filter, respectively, and $\omega_{c}$ is the cut-off frequency of the filter.

Assume the real stator flux can be expressed as

$$
\begin{aligned}
& \lambda_{d s}^{s}=\lambda_{s} \cdot \cos \left(\omega_{e} t\right) \\
& \lambda_{q s}^{s}=\lambda_{s} \cdot \sin \left(\omega_{e} t\right)
\end{aligned}
$$

where $\lambda_{s}$ is the stator flux amplitude, and $\omega_{e}$ is the electrical frequency.

Substituting (26) and (27) into (20) and (21), the real back EMF can be expressed as

$$
\begin{aligned}
& e_{d s}^{s}=-\omega_{e} \lambda_{s} \cdot \sin \left(\omega_{e} t\right) \\
& e_{q s}^{s}=\omega_{e} \lambda_{s} \cdot \cos \left(\omega_{e} t\right) .
\end{aligned}
$$

To implement the stator flux estimator (24) and (25), we need to measure the stator current. In general, the feedback signal will be polluted by the dc offset; therefore, it is reasonable to describe the estimated back EMF $\hat{e}_{d s}^{s}$ and $\hat{e}_{q s}^{s}$ as

$$
\begin{aligned}
& \hat{e}_{d s}^{s}=-\omega_{e} \lambda_{s} \cdot \sin \left(\omega_{e} t\right)+v_{\text {off }} \\
& \hat{e}_{q s}^{s}=\omega_{e} \lambda_{s} \cdot \cos \left(\omega_{e} t\right)+v_{\text {off }}
\end{aligned}
$$

where $v_{\text {off }}$ is the dc offset of the feedback signals.

Substituting (30) and (31) into (24) and (25), the estimated flux $\hat{\lambda}_{d s}^{f}$ and $\hat{\lambda}_{q s}^{f}$ can be expressed as

$$
\begin{aligned}
& \hat{\lambda}_{d s}^{f}=k_{d} \cdot e^{-\omega_{c} t}+\frac{v_{\mathrm{off}}}{\omega_{c}}+A_{f} \cdot \lambda_{s} \cdot \cos \left(\omega_{e} t+\Delta \varphi\right) \\
& \hat{\lambda}_{q s}^{f}=k_{q} \cdot e^{-\omega_{c} t}+\frac{v_{\mathrm{off}}}{\omega_{c}}+A_{f} \cdot \lambda_{s} \cdot \sin \left(\omega_{e} t+\Delta \varphi\right)
\end{aligned}
$$

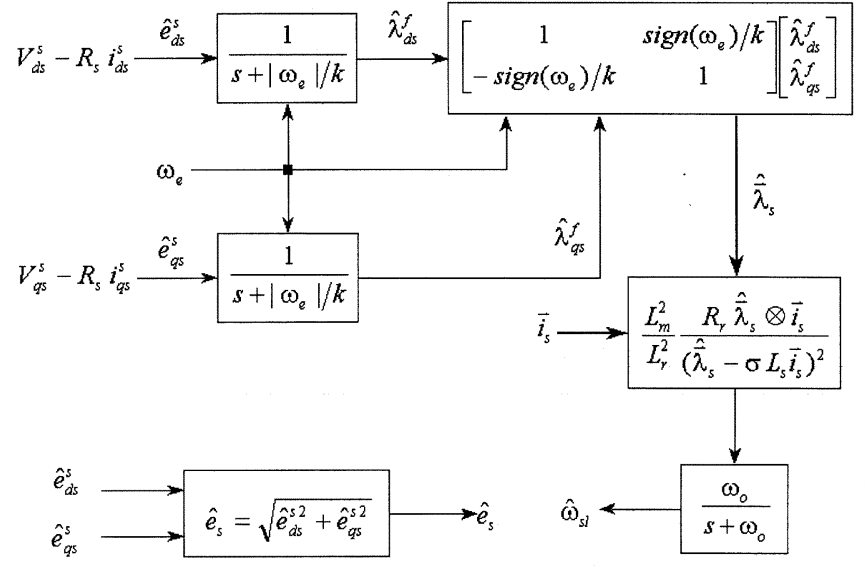

Fig. 3. Block diagram of the stator flux and slip frequency estimator with an accurate matrix.

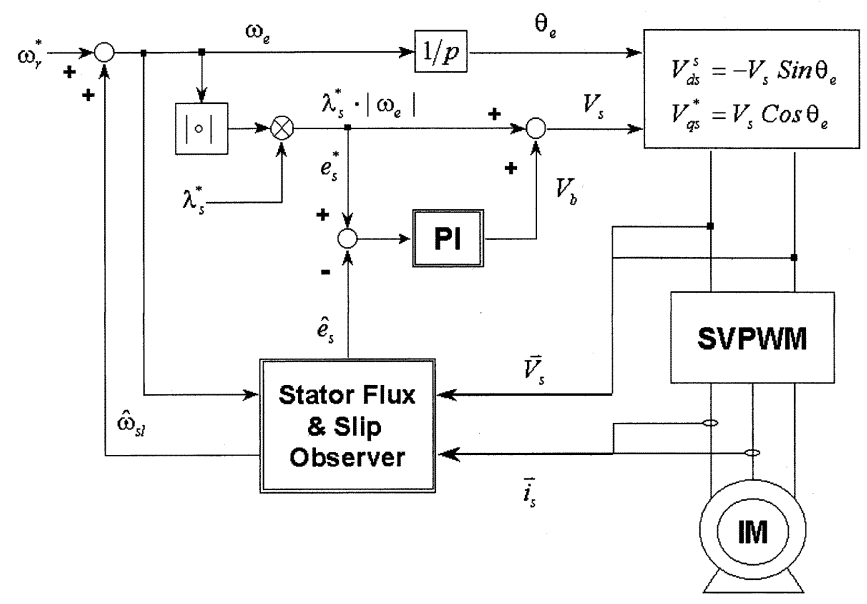

Fig. 4. Overall block diagram of the proposed sensorless scalar control system.

where $k_{d}$ and $k_{q}$ are constant values, which correlate with the initial values and dc offset, and $A_{f}$ and $\Delta \varphi$ are the amplitude attenuation ratio and phase shift between the estimated flux and the real flux and can be expressed as

$$
A_{f}=\frac{\left|\omega_{e}\right|}{\sqrt{\omega_{e}^{2}+\omega_{c}^{2}}}, \quad \Delta \varphi=\tan ^{-1}\left(\frac{\omega_{c}}{\omega_{e}}\right) .
$$

Comparing (32) and (33) with (26) and (27), we expect a large $\omega_{c}$ to reduce the effects of the initial value errors and dc offset and a small $\omega_{c}$ to increase the ratio of $A_{f}$. To balance these two requests, we adopt the estimator structure proposed in [11] to estimate the stator flux, in which the cut-off frequency of the highpass filter is proportional to the electrical frequency, i.e.,

$$
\omega_{c}=\frac{\omega_{e}}{k} \text {. }
$$

Substituting (35) into (34), the amplitude attenuation ratio and phase shift can be simplified as

$$
A_{f}=\frac{k}{\sqrt{k^{2}+1}}, \quad \Delta \varphi=\operatorname{sign}\left(\omega_{e}\right) \cdot \tan ^{-1}\left(\frac{1}{k}\right) .
$$

The $A_{f}$ and $\Delta \varphi$ in (36) are both constant. Therefore, the estimated stator flux can be corrected easily with a constant matrix. Fig. 3 presents the black diagram of the stator flux and slip frequency estimator. In Fig. 3 , the $\hat{e}_{s}$ denotes the amplitude of the 


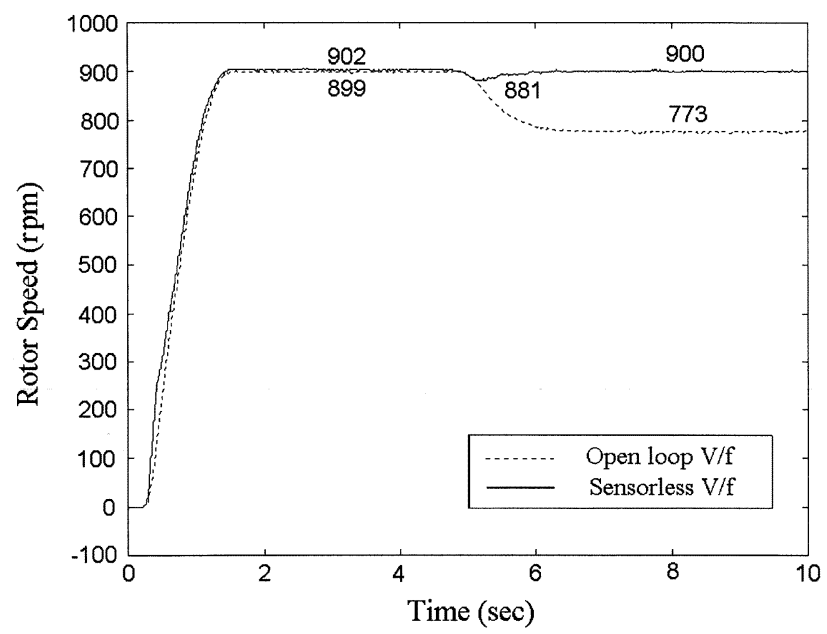

(a)

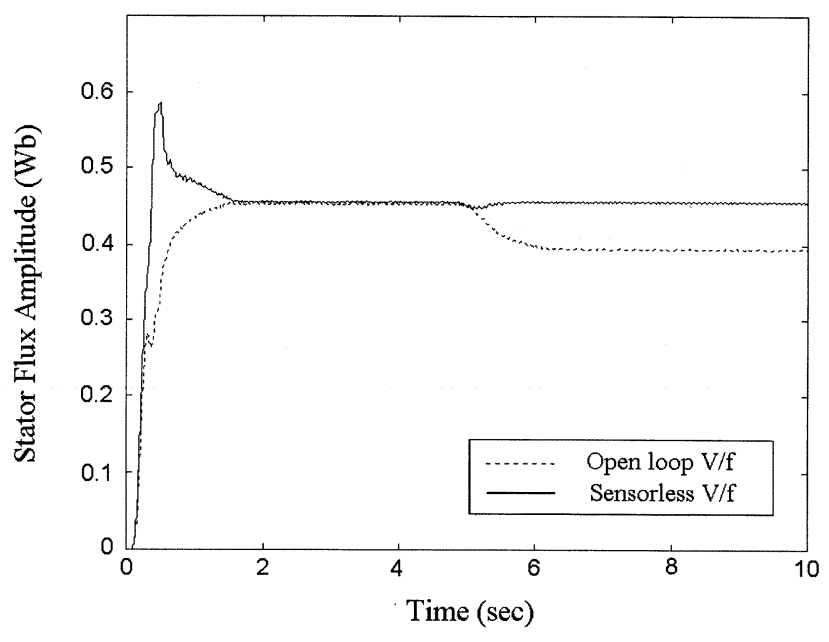

(c)

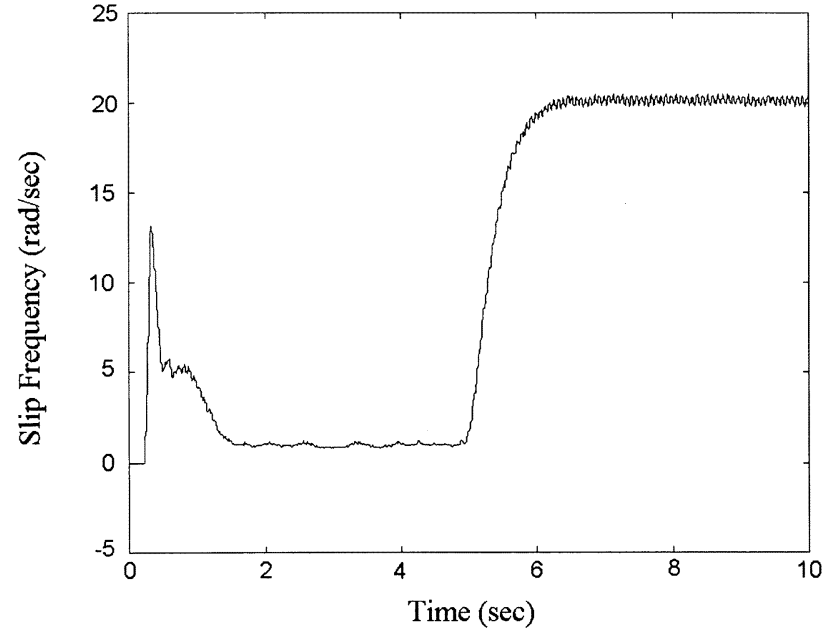

(b)

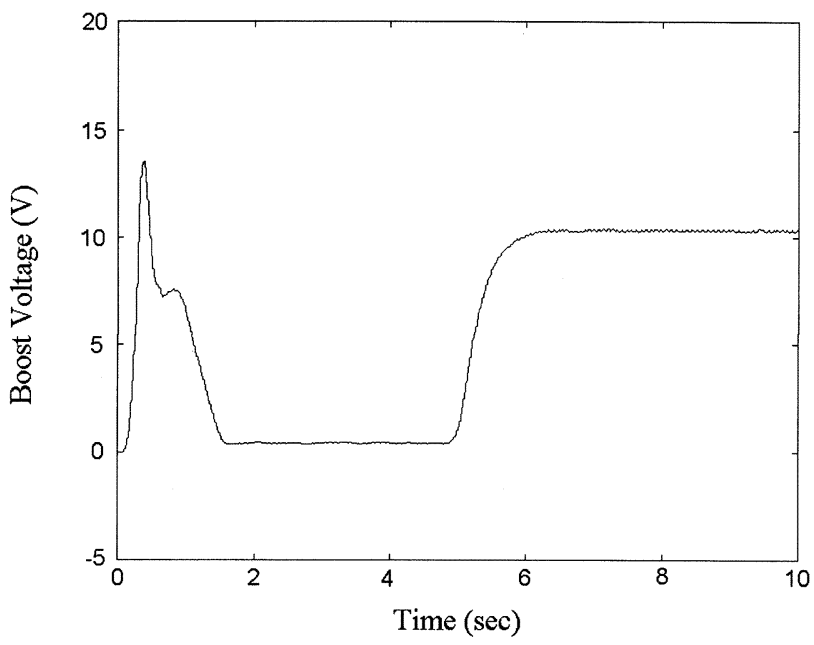

(d)

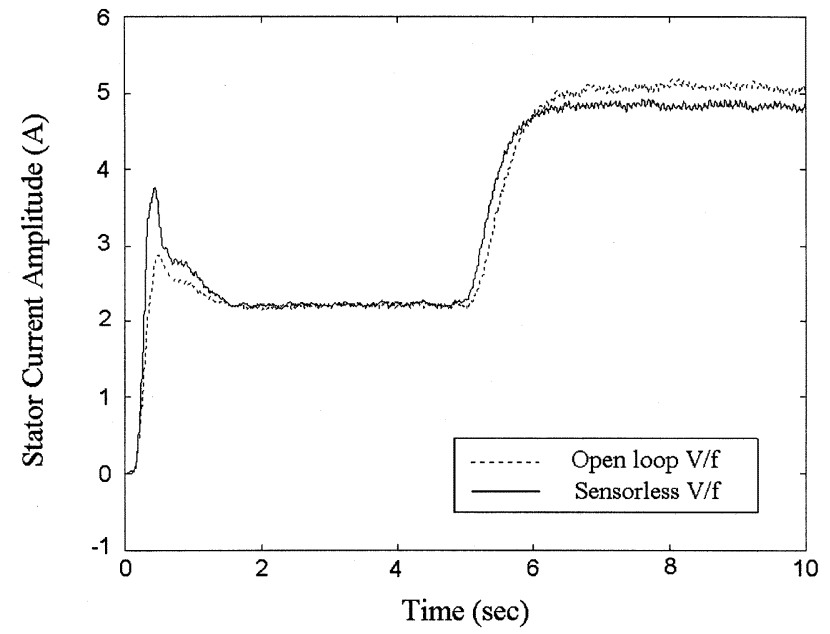

(e)

Fig. 5. Experimental results of the open-loop scalar control method and the proposed sensorless scalar control method at $\omega_{r}^{*}=900 \mathrm{r} / \mathrm{min}$ with a load change from no load to the rated load. (a) Speed. (b) Slip. (c) Amplitude of stator flux. (d) Boost voltage. (e) Amplitude of stator current.

back EMF, which will be applied to control the amplitude of the stator flux within the boost controller. To keep the amplitude ratio $A_{f}$ large enough, such as 0.95 , the value of $k$ in (35) is selected as 3 in the following experiments. 


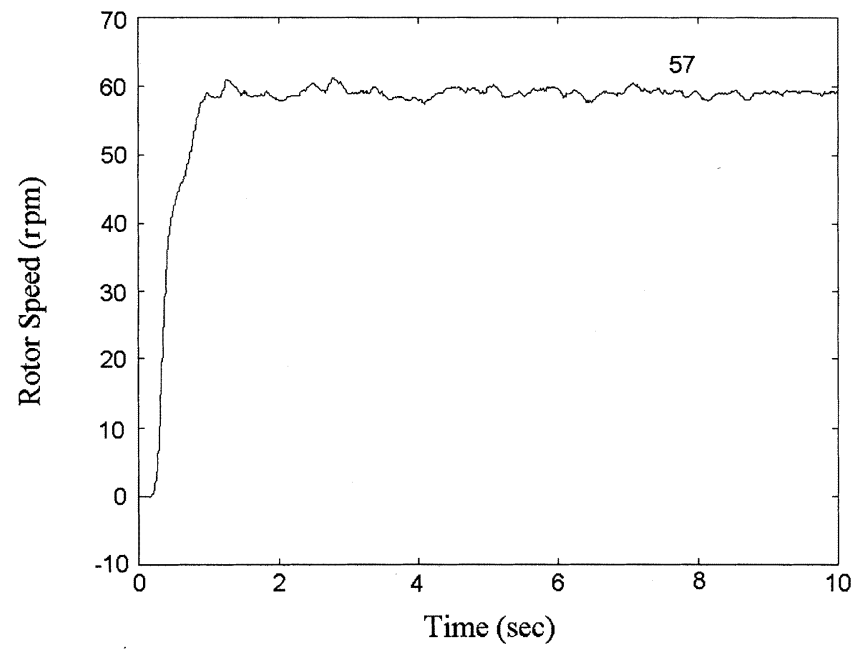

(a)

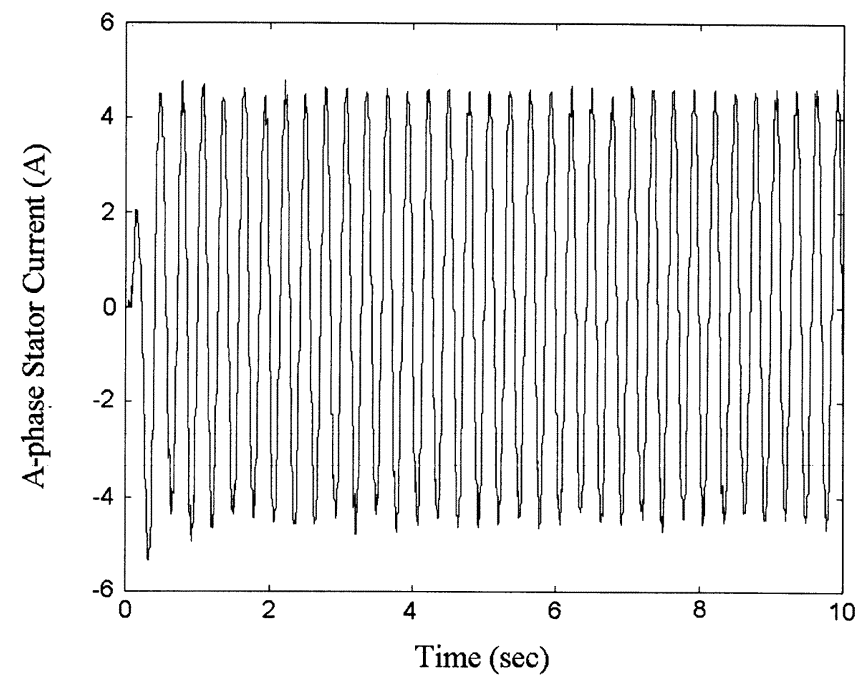

(b)

Fig. 6. Speed and A-phase current waveforms of the proposed sensorless control method under the rated load at $\omega_{r}^{*}=60 \mathrm{r} / \mathrm{min}$

\section{EXPERIMENTAL RESULTS}

Fig. 4 illustrates schematically the overall block diagram of the proposed sensorless scalar control for the induction motor drive. In Fig. 4, a boost voltage controller is applied to control the flux amplitude. To reduce the effect of the estimated flux error on the flux control, the back EMF error is applied to regulate the boost voltage. Furthermore, to investigate the feature of the proposed controller in Fig. 4, an experimental design is assembled. The primary components of this design are one 586-K personal computer (PC) with a servo control card insert into its ISA bus, which has eight 12 bit A/D converters, four D/A converters, and a 16-bit encoder counter. In addition, there is a ramp comparison voltage-fed inverter, a 1-hp, 220-V, 3.4-A, and $1700 \mathrm{r} / \mathrm{min}$ induction motor with a 1000 pulses/rev optical encoder, and a magnetic powder brake system to simulate the mechanical load. The sampling period of the control program was selected as $0.5 \mathrm{~ms}$.

Fig. 5 presents the experimental results of the open-loop scalar control method and the proposed sensorless scalar control method at $\omega_{r}^{*}=900 \mathrm{r} / \mathrm{min}$ with a load increased from no load to the rated load. In a no-load condition, both control

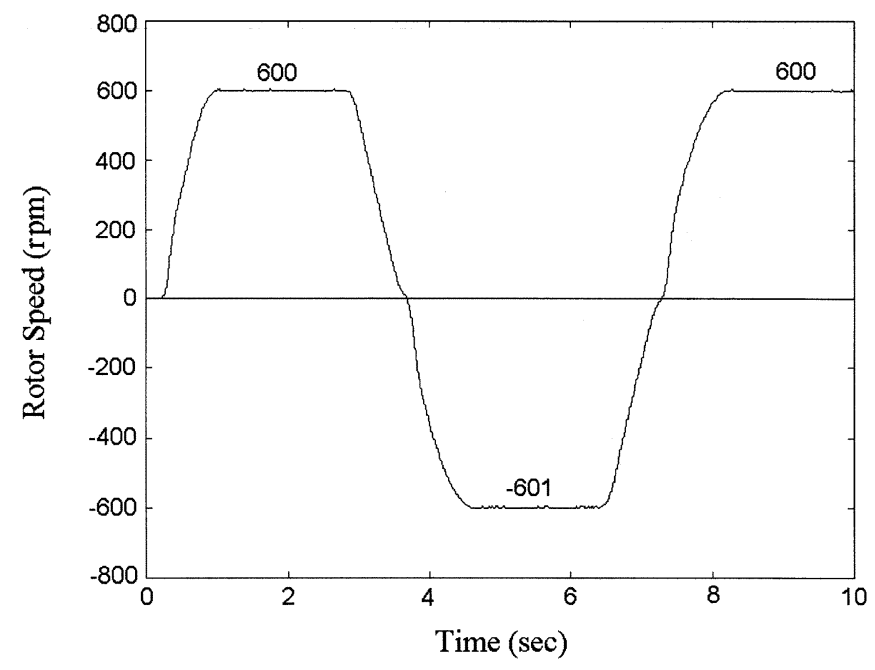

(a)

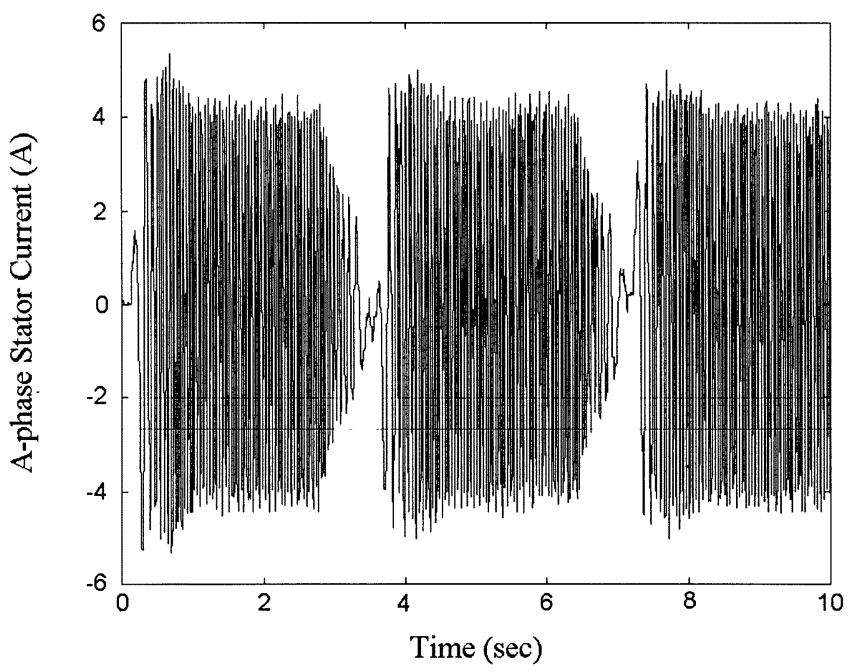

(b)

Fig. 7. Speed and A-phase current waveforms of the proposed sensorless control method during speed reversal operation $\left(\omega_{r}^{*}= \pm 600 \mathrm{r} / \mathrm{min}\right)$ and under the rated load condition.

methods display commendable speed accuracy [see Fig. 5(a)]. Alternately, when the rated load is applied to the rotor axis, a massive speed error of nearly $127 \mathrm{r} / \mathrm{min}$ occurs due to the open-loop scalar control method. However, as depicted in Fig. 5(b), the proposed sensorless scalar control method estimates the slip frequency and, thus, compensates the electrical frequency command. Therefore, as Fig. 5(a) illustrates, when the load fluctuates, speed accuracy remains intact. In the proposed sensorless control method, when the load fluctuates, the auto-boost controller regulates the boost voltage and maintains a constant flux [see Fig. 5(c) and (d)]. Furthermore, when a rated load is applied, the stator flux amplitude of the open-loop scalar control method is decreased, and thus, additional stator current is required to produce the same torque, as demonstrated in Fig. 5(e). In addition, Fig. 6 depicts the speed and the A-phase current waveforms of the proposed sensorless control method under the rated load at $\omega_{r}^{*}=60 \mathrm{r} / \mathrm{min}$. Fig. 6(a) presents an acceptable speed response, and although a small oscillation occurs, the stead state error is maintained at approximately $3 \mathrm{r} / \mathrm{min}$. Fig. 7 


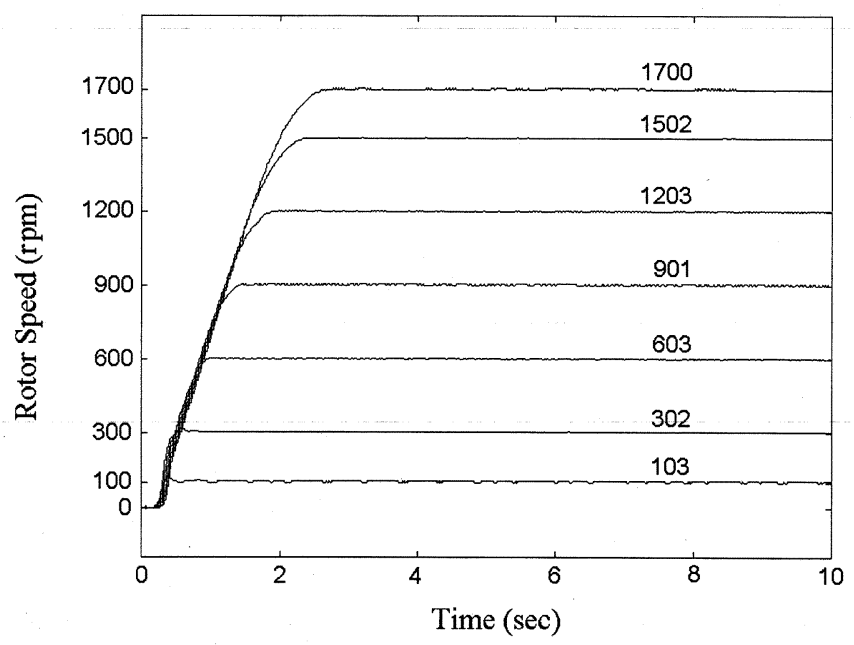

(a)

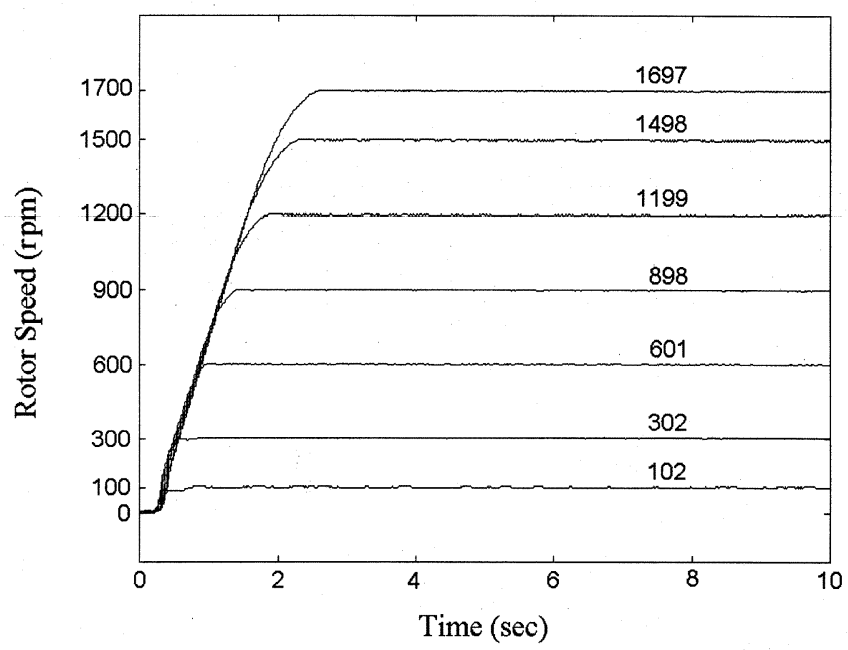

(b)

Fig. 8. Measured speed response of the speed reference at 100, 300, 600, 900, 1200,1500 , and $1700 \mathrm{r} / \mathrm{min}$ for the sensorless scalar controller under. (a) No load. (b) Full load.

displays the experimental waveforms of the proposed sensorless control method during speed reversal operation and subjected to the rated load condition. In this instance, although the speed reference varies from $+600 \mathrm{r} / \mathrm{min}$ to $-600 \mathrm{r} / \mathrm{min}$, it returns to $+600 \mathrm{r} / \mathrm{min}$. Notably, a stable four-quadrant operation is obtained [see Fig. 7(a)]. Fig. 8 depicts the speed response of the proposed method at various speed references under no load and at the rated load condition. Excellent speed control response is evident in these experimental results. In addition, the steady-state speed error remained less than $5 \mathrm{r} / \mathrm{min}$ [see Fig. 8(a) and (b)].

\section{CONCLUSION}

In this study, a very simple sensorless scalar control algorithm for the induction motor has been proposed. First, based on the mathematical model of the induction motor, a modified flux observer and a corrected matrix are employed to estimate the stator flux and calculate the slip frequency. Then, to regulate motor speed, the estimated slip frequency was added to the scalar con- trol method. In the proposed control structure, an auto-boost controller is applied to maintain a constant stator flux amplitude. Finally, to demonstrate the proposed control algorithm in a 1-hp induction motor, a PC-based experimental system was constructed. Experimental results confirm the efficiency of the proposed algorithm for induction motor drives.

\section{REFERENCES}

[1] P. Vas, Vector Control of AC Machines. New York: Clarendon, 1990.

[2] B. K. Bose, Power Electronics and AC Drives. Englewood Cliffs, NJ: Prentice-Hall, 1986.

[3] C. J. Bonanno, L. Zhen, and L. Xu, "A direct field oriented induction machine drive with robust flux estimator for position sensorless control," in Proc. IEEE-IAS Annu. Meeting, 1995, pp. 166-173.

[4] C. Schauder, "Adaptive speed identification for vector control of induction motors without rotational transducers," IEEE Trans. Ind. Applicat., vol. 28, pp. 1054-1061, Sept./Oct. 1992.

[5] F. Z. Peng and T. Fukao, "Robust speed identification for speed-sensorless vector control of induction motors," IEEE Trans. Ind. Applicat., vol. 30, pp. 1234-1240, Sept./Oct. 1994.

[6] H. Kubota and K. Matsuse, "Speed sensorless field-oriented control of induction motor with rotor resistance adaptation," IEEE Trans. Ind. Applicat., vol. 30, pp. 1219-1224, Sept./Oct. 1994.

[7] G. Yang and T. H. Chin, "Hyperstability of the full-order observer for vector-controlled induction motor drive without speed sensor," Elect. Eng. Jpn., vol. 113, no. 1, pp. 109-118, 1993.

[8] J. S. Lee, T. Takeshita, and N. Matsui, "Stator-flux-oriented sensorless induction motor drive for optimum low-speed performance," IEEE Trans. Ind. Applicat., vol. 330, pp. 1170-1176, Sept./Oct. 1997.

[9] B. K. Bose and N. R. Patel, "A programmable cascaded low-pass filterbased flux synthesis for a stator flux-oriented vector-controlled induction motor drive," IEEE Trans. Ind. Electron., vol. 44, pp. 140-143, Jan. 1997.

[10] J. Hu and B. Wu, "New integration algorithms for estimation motor flux over a wide speed range," in Proc. IEEE Power Electron. Specialist's Conf., 1997, pp. 1075-1081.

[11] M. H. Shin, D. S. Hyun, S. B. Cho, and S. Y. Choe, "An improved stator flux estimation for speed sensorless stator orientation control of induction motors," IEEE Trans. Power Electron., vol. 15, pp. 312-318, Feb. 2000

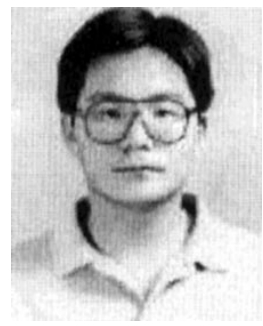

Chun-Chieh Wang was born in Taiwan, R.O.C., in 1967. He received the B.S. degree in nuclear engineering from National Tsing Hua University, Hsinchu, Taiwan, in 1990, and the Ph.D. degrees in electrical engineering from National Taiwan Institute of Technology, Taipei, Taiwan, R.O.C., in 1997.

From 1997 to 1999, he was a research scientist at Industrial Technology Research Institute, Hsinchu. Since 1999, he has been with the Department of Electrical Engineering, Ching Yun Institute of Technology, Jung-Li, Taiwan, where he is currently an Assistant Professor. His research interests include adaptive control, variable structure control, and electric motor control.

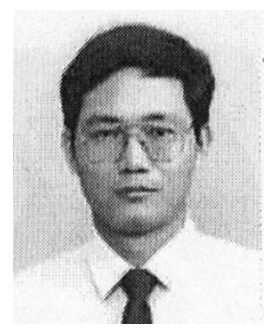

Chih-Hsing Fang was born in Taiwan, R.O.C., in 1956. He received the B.S. degree in automatic control engineering from the Private Feng-Chia University, Taichung, Taiwan, R.O.C., and the M.S. degree in electrical engineering from the Chung-Cheng Institute of Technology, Tao-Yoan, Taiwan, in 1980 and 1987, respectively. He is currently pursuing the Ph.D. degree at the Department of Electronic and Control Engineering, National Chiao Tung University, Hsinchu, Taiwan, R.O.C.

Since 1991, he has been with the Industry Technology Research Institute, Hsinchu, as a design engineer of the induction heating and inverter. His research interests include ac motor drives, control theory applications, and digital signal processing applications in power electronics. 